\title{
Helicobacter pylori Eradication Therapies in the Era of Increasing Antibiotic Resistance: A Paradigm Shift to Improved Efficacy
}

\author{
Sotirios D. Georgopoulos, ${ }^{1}$ Vasilios Papastergiou, ${ }^{2}$ and Stylianos Karatapanis ${ }^{2}$ \\ ${ }^{1}$ Department of Gastroenterology, Athens Medical Center of P. Phaliron, P. Phaliron, 17562 Athens, Greece \\ ${ }^{2}$ Department of Internal Medicine, General Hospital of Rhodes, 85100 Rhodes, Greece \\ Correspondence should be addressed to Stylianos Karatapanis, stylkar@otenet.gr
}

Received 3 March 2012; Accepted 8 May 2012

Academic Editor: Ping-I Hsu

Copyright (C) 2012 Sotirios D. Georgopoulos et al. This is an open access article distributed under the Creative Commons Attribution License, which permits unrestricted use, distribution, and reproduction in any medium, provided the original work is properly cited.

\begin{abstract}
With the rising prevalence of antimicrobial resistance, the eradication rates of Helicobacter pylori (H. pylori) with standard treatments are decreasing to unacceptable levels (i.e., $\leq 80 \%$ ) in most countries. After these disappointing results, several authorities have proposed that infection with $H$. pylori should be approached and treated as any other bacterial infectious disease. This implicates that clinicians should prescribe empirical treatments yielding a per protocol eradication of at least $90 \%$. In recent years several treatments producing $\geq 90 \%$ cure rates have been proposed including sequential therapy, concomitant quadruple therapy, hybrid (dual-concomitant) therapy, and bismuth-containing quadruple therapy. These treatments are likely to represent the recommended first-line treatments in the near future. In the present paper, we are considering a series of critical issues regarding currently available means and approaches for the management of $H$. pylori infection. Clinical needs and realistic endpoints are taken into account. Furthermore, emerging strategies for the eradication of $H$. pylori and the existing evidence of their clinical validation and widespread applicability are discussed.
\end{abstract}

\section{Introduction}

Infection with Helicobacter pylori (H. pylori) is a global health problem affecting $20-50 \%$ of the western world's population and up to $80 \%$ of the population in developing countries [ 1 , 2]. Presence of $H$. pylori is known to be associated with a wide range of gastrointestinal disorders including peptic ulcer, gastric carcinoma, and mucosa-associated tissue lymphoma, and, thus, ability to reliably eradicate the pathogen is important for managing these diseases [3-6]. Several factors are making infection with $H$. pylori so challenging to treat. These factors include (a) the development of $H$. pylori resistance to antibiotics, (b) the large number of bacteria in the stomach, producing an "inoculum" effect, (c) the protection of the thick gastric mucus gel layer, and (d) the intracellular (and thus inaccessible to antibiotics) location of many bacteria [7-9]. Other factors including presence of multiple strain infection and individual factors such as patient's compliance to treatment, age less than 60 , the type of gastritis, and presence of nonulcer dyspepsia, where the eradication rates are lower in comparison with peptic ulcer disease, have been also linked to therapy efficacy $[10,11]$. Educating the patient on the importance to take the medication as prescribed, warning in advance on the possibility of adverse events, and therefore obtain the maximum in terms of compliance to treatment poses a major clinical challenge to practicing physicians.

Historically, a wide spectrum of antimicrobial agents have been shown to be effective against $H$. pylori and successfully used in clinical practice. Most commonly are clarithromycin, amoxicillin, metronidazole, tinidazole, tetracycline, and the fluoroquinolones. As experience in treating the infection was gained, these drugs (and with the addition of an antisecretory agent or bismuth) have been used in different combinations, and developed regimens have been tailored in various parameters (dosage, dosing intervals, 
duration of treatment) in order to provide the best outcome in terms of efficacy and tolerability. However, despite the continuous efforts made by the digestive disease community (and not by experts in infectious diseases), the optimal empirical treatment remains to be discovered.

In the present paper we are considering a series of critical issues regarding currently available means and approaches for the management of $H$. pylori infection. Realistic needs are taken into account with particular attention to crucial aspects for clinical practice and the importance for posttreatment testing for cure. Furthermore, emerging strategies for the eradication of $H$. pylori and the existing evidence of their clinical validation and applicability are discussed.

\section{Empirical Triple Therapies: A Declining Clinical Standard}

More than a decade ago, recommended therapies comprising of a proton pump inhibitor (PPI), amoxicillin, and clarithromycin (standard triple therapies) yielded high efficacy, providing eradication rates comparable to those expected for other prevalent bacterial infections such as respiratory and urinary tract infections, gonorrhea, and tuberculosis $[12,13]$. Unfortunately, in successive years the eradication rates have fallen considerably with these regimens, in some countries to unacceptably low levels $(<80 \%$ or even $<70 \%)$, mainly because of the increasing prevalence of resistance to clarithromycin $[8,14,15]$. The widespread use of clarithromycin for infectious diseases other than $H$. pylori infection represents the main reason for the increasing development of resistance to this antibiotic; this explains the lower prevalence of clarithromycin resistance in Northern (versus Southern) European countries where policy for antibiotic use is more stringent [16]. The progressive decline in the efficacy of first-line treatments was already evident in the first metaanalyses published by the early 2000s and indirectly outlined by the European consensus recommendations (Maastricht 2000 and 2005), initially with the adoption of a "cumulative" approach to treat $H$. pylori, which introduced first- and second-line therapies, and later by the definition of a local/ regional threshold of resistance to clarithromycin (15-20\%), at which the antibiotic should not be used if culture was not previously performed to assess susceptibility [17-20]. In such cases, a bismuth-containing quadruple therapy (comprising of PPI, bismuth, metronidazole, and tetracycline) is recommended as an alternative empirical treatment, although its efficacy does not seem to exceed that of standard regimen according to some studies and a recent metaanalysis [21-23]. Furthermore, the threshold of resistance to clarithromycin at which triple regimens lose their efficacy seems to be substantially lower than $15-20 \%$ and may be $10 \%$ or even less [24].

Currently, standard triple therapy still remains the most widely recommended first-line treatment option worldwide and even in countries where improved alternative therapeutic options have been developed and sufficiently validated in a clinical setting [25-27]. The situation is similar in Greece: triple therapies represent the backbone of routine clinical practice but their performance is steadily declining during the past 10 years [28-31], in parallel with an increase in the incidence of clarithromycin resistance, reportedly from $6 \%$ to $26 \%$ [32-34].

To be fair, the cumulative efficacy of first and secondline treatments proposed by Maastricht 3, together with sensitivity-directed (re)treatment or administration of 3rd and 4 th line rescue therapies (based on levofloxacin and rifampicin, resp.), is nearly approaching $100 \%[31,35,36]$. However, for this goal to be achievable, patients must be highly compliant with repeated treatment courses. Necessity to use second-line therapies accounts for $20-30 \%$ of patients infected with $H$. pylori (intention to treat (ITT) analysis); even second-line therapy is not enough to eradicate the pathogen in $5-10 \%$ of cases $[31,37]$. These rates are likely to increase further, as antimicrobial resistance becomes more prevalent worldwide. In that setting, patients may be required to complete more than one (and sometimes 3 or 4) complex treatment courses and therefore be exposed to a significant range of potential side effects which can virtually affect adherence and compromise their quality of life.

Use of an effective first-line treatment is known to provide a key advantage in the eradication of $H$. pylori, namely, prevention of secondary antibiotic resistance [38]. Much effort has been spent on improving currently recommended treatments. However, attempts to increase the duration of triple therapy, thus prolonging the exposure to antibiotics, have not resulted in a substantial benefit. There is therefore a clear need for novel therapeutic strategies.

\section{A Paradigm Shift to Improved Efficacy}

H. pylori is a major human pathogen which causes a serious, transmissible, infectious disease leading to significant morbidity. However, in contrast to what is common practice in other bacterial infections (where selection of the optimal therapy is usually based on susceptibility testing), first-line therapies against $H$. pylori are only prescribed empirically. This implicates that new regimens should be properly optimized (in terms of dosage, duration of treatment, dosing intervals, and local antimicrobial resistance pattern) before their introduction in clinical practice. Moreover, resolution of the infection should be always confirmed, preferably by using a noninvasive test, providing clinicians with a reliable measure of the local drug resistance. More intuitively, optimal eradication of $H$. pylori has to follow two golden rules: (1) always choose the best available first-line treatment (i.e., the one that works best locally) and (2) always confirm the success of therapy by posttreatment testing and retreat patients who fail to eradicate $H$. pylori. Adoption of these two rules will guarantee for patients the best chance to be treated, with the minimum cost in terms of treatment-related adverse events and will create a useful feedback for practicing clinicians, which will prevent them from prescribing locally unacceptable regimens.

Current approach to treatment of $H$. pylori infection is challenged by the declining efficiency of standard firstline therapies, leading to increasing need for second-line 
(or more) treatment courses. Paradoxically, since the initial developments in the field, infection from $H$. pylori has been approached by the digestive disease community (and not by experts in infectious diseases), as any other gastrointestinal disease (e.g., inflammatory bowel disease or irritable bowel syndrome): in the absence of an optimal treatment, the best available therapies are offered in sequence. On the contrary, for most common infections, treatment success is expected to be near $100 \%$ (i.e., $\geq 95 \%$ ). It becomes clear that a "paradigm shift" (i.e., a change from one way of thinking to another) is necessary in order for the field to move forward [39]. Indeed, several authorities have proposed that infection with $H$. pylori should be approached and treated as any other bacterial infectious disease [40-42]. This implicates, as a general rule, that clinicians should prescribe therapeutic regimens that have a per protocol (PP) eradication rate of at least 90\% (grade B level) and probably at least 95\% (grade A level), in keeping with the existing practice in the field of other common bacterial infectious diseases [40, 41].

Development of secondary resistance (i.e., as the result of failed therapy) is largely responsible for the decline in eradication rates. Owing to this conception treatment of $H$. pylori infection is becoming a hit or miss process aiming to decrease the number of eradication failures as much as possible. As stated in the present paper, infection with $H$. pylori should be treated as any other infectious disease, and, thus, ideally, a regimen should be based on pretreatment drug susceptibility testing. In spite of this, routine use of endoscopy is not feasible and not well tolerated by all patients. Moreover, the high economic burden related to this procedure together with the disappointing results often observed in vivo by following in vitro susceptibility is largely limiting cost efficacy of culture-guided therapy. On the contrary, enhancement of the eradication rate to values approaching $90 \%$ by adopting novel and possibly less expensive eradication strategies seems to represent a fascinating alternative.

In recent years, promising new treatment strategies have been proposed and largely validated in some countries and are likely to represent the recommended first-line therapies in the near future [42]. Emerging first-line treatments achieving high eradication rates of $90 \%$ or more (PP analysis) are discussed below. However, it should be noted that eradication rates reported further in this paper may be prone to wide geographic variability secondary to critically important differences in the local background rates of antibiotic resistance. As empiric treatments are given without antimicrobial susceptibility testing, the choice of an empiric therapy should rely on knowledge that the combination is successful in the local population.

\section{Emerging First-Line Treatments with a Per-Protocol Eradication Rate Exceeding 90\%}

4.1. Sequential Therapy. One recent innovation postulated as an alternative to standard triple therapy is sequential treatment, which involves a simple dual regimen including a PPI plus amoxicillin for the first 5 days followed by a triple regimen including a PPI, clarithromycin and tinidazole for the following 5 days [43]. It represents the most extensively evaluated novel therapeutic strategy including 5 comparative meta-analyses and one pooled data analysis reporting on its efficacy and safety profile [43-48].

In the most recent meta-analysis of 15 randomized studies (published until May 2009, including 3346 patients), sequential therapy has been demonstrated to be superior to legacy triple therapy for the eradication of H. pylori $(91.7 \%$, 95\% Confidence Interval (CI): 90-93\% versus 76, 7\%, 95\% CI: $75-79 \%$, ITT analysis) [43]. Interestingly, this regimen demonstrated ITT cure rates higher than 90\% (grade B), even in countries with a high prevalence of resistance to clarithromycin, demonstrating higher performance (versus standard triple regimen) to eradicate clarithromycinresistant strains [42]. In the meta-analysis by Gisbert et al., 41 out of 55 (75\%) clarithromycin-resistant strains (4 studies) were eradicated after exposure to sequential therapy [43], although the total number with clarithromycin resistance in the included studies is still low for definite conclusions to be drawn. Similarly, the sequential regimen has been suggested as superior to legacy triple therapy in patients with metronidazole resistance $[43,48]$. On the other hand, and despite this increased efficiency (in comparison with standard therapies) against sensitive and monoresistant strains, the performance of the sequential regimen seems to be dramatically compromised in the presence of dual antibiotic resistances (clarithromycin and imidazole) $[49,50]$. Although the working mechanisms of the improved efficacy of the sequential regimen remain to be fully elucidated, some hypotheses may be put forward. It has been speculated that the disruption of the bacterial wall caused by amoxicillin could prevent the development of efflux channels for clarithromycin, which are known to rapidly transfer the drug out of the bacterial cell preventing the binding to the ribosome. However, according to another hypothesis, the improved effect with sequential therapy may be not attributed to the sequential administration itself; the bacteria may be simply "fulminated" by the larger number of antibiotics ( 3 together) to which the organism is exposed [51-53]. In accordance with this last scenario, concurrent administration of the same 3 antibiotics for a longer period of 7-10 days (i.e., the concomitant therapy, discussed further in this paper) has been shown to confer an acceptable eradication rate ( $89 \%$ by PP analysis and $87 \%$ by ITT analysis) when prescribed in a setting of high clarithromycin resistance $(20 \%)$ where sequential regimen has been previously proved to be ineffective (cure rate 76\%) [54, 55]. This data may represent preliminary, although indirect, evidence that sequential administration is probably more complicated than really necessary.

Indeed, a major shortcoming for the use of the sequential regimen is its complexity. Although adherence to treatment was excellent in the context of clinical trials, requiring the patient to switch from a dual to a triple therapy at midpoint could inherently interfere with compliance, if this regimen is prescribed in a real clinical practice setting [56-60]. Nonetheless, almost all studies proposing sequential therapy have been conducted in Italy. Importantly, in contrast to the initial studies showing a mean overall performance 
approaching 90\%, more recent studies conducted outside this country have shown a tendency towards lower eradication rates; in particular when dual antibiotic resistance is present [55, 61-68]. Further validation is therefore necessary before this regimen can be considered for widespread recommendation in clinical practice.

4.2. Nonbismuth Quadruple (Concomitant) Therapy. The concomitant regimen involves the concurrent administration of all three antibiotics used in first-line triple therapies (amoxicillin, clarithromycin, and metronidazole) given together with a PPI, all twice daily, for at least 10 days [50, 69]. This regimen is not completely novel; it has been previously evaluated with shorter durations of administration (3-7 days), in studies published between 1998 and 2002, allowing for high eradication rates (89-94\% on ITT analysis) $[70,71]$. It reappears nowadays as a 10 -day regimen leading to eradication rates exceeding $90 \%$ on ITT analysis $[50,72]$. In contrast to the sequential regimen, which has been developed and mostly evaluated in Italy, concomitant therapy has been tested in a wider range of geographical areas (including Japan, Germany, Colombia, Taiwan, and Greece) [42]. The ideal duration of administration remains an issue as direct comparisons between variable durations of treatment (e.g., 5 days versus 7 days versus 10 days) are lacking. However, one can speculate that, due to the increased antibiotic resistance rates, 3 - and 5-day concomitant regimens may not be suitable today [67]. Interestingly, in a pilot study, the combination of sequential and concomitant therapies given for 14 days (hybrid therapy, PPI and amoxicillin for 7 days followed by PPI and all three antibiotics for another 7 days) achieved impressively high eradication rates (99\% and $97 \%$ on PP and ITT analysis, resp.) (grade A level) [73].

In Greece, a country with high resistance rates to both clarithromycin and metronidazole ( $>20 \%$ for clarithromycin and $>40 \%$ for metronidazole), concomitant therapy has been introduced since the beginning of 2009 achieving excellent therapeutic results with cure rates of $91.6 \%$ on ITT and $94.5 \%$ on per PP analysis (grade B) [74]. It seems that concomitant therapy eradicates more than $60 \%$ of doubleresistant $H$. pylori strains and the vast majority of sensitive and monoresistant strains, thus preventing the emergence of secondary resistance [75]. At the same time, means of tolerability and safety profile are reported to be excellent and comparable to those obtained with standard triple therapy $[74,75]$.

A main advantage of the concomitant (versus sequential) therapy may be represented by its suitability for patients with dual resistance to antibiotics. Indeed, in a comparative study by $\mathrm{Wu}$ et al., patients with resistance to both clarithromycin and metronidazole had significantly lower eradication rates after sequential therapy (present versus absent: $33.3 \%$ versus 95.1\%; $P$-value $<0.0001)$, but not after concomitant therapy (present versus absent: $75.0 \%$ versus $92.4 \% ; P$-value $=0.22$ ) [50]. However, it should be noted that this study was conducted in Taiwan where the rate of antibiotic resistance is very low and even standard triple therapy is currently yielding excellent eradication rates [76]. A comparison study conducted across a broad range of patients and with a high prevalence of antibiotic-resistant $H$. pylori strains would be therefore much appreciated in order to definitely solve the issue of concurrent versus sequential administration; these two emerging treatment options seem to represent the main competitors likely to replace triple therapy in the foreseeable future.

4.3. Bismuth-Containing Quadruple Therapy. This regimen is mainly used as second-line treatment when legacy triple therapy fails, but also as an alternative first-line treatment option in regions with a high incidence of resistance to clarithromycin [77]. Other than working independently from resistance to clarithromycin, the main advantage of this regimen is represented by the limited clinical impact of metronidazole resistance which can be largely overcome by increasing the dose of metronidazole and duration of treatment. Considering that resistance to metronidazole in most countries is currently exceeding $10 \%$, the daily dose of metronidazole prescribed should be approximately $1500 \mathrm{mg}$ ( $3 \times 500$ or $4 \times 400 \mathrm{mg}$ in England) in order for maximal cure rates to be obtained.

Historically, in an early meta-analysis, first-line use of a bismuth-containing quadruple therapy (BQT) yielded high eradication rates (grade A or B level) [78]. These encouraging results have been mainly attributed to the efficacy against metronidazole-resistant strains, which overcome the eradication achieved with standard triple therapy over clarithromycin-resistant strains $[23,79]$. However, according to a more recent meta-analysis, performance of both BQT and standard regimen was suboptimal $(78.3 \%$ versus $77 \%$ on ITT analysis) [23]. In our country, BQT has been mainly used as a second-line therapy leading to rather contradictory results $[28,80]$. In the only study where BQT has been used as first-line treatment and compared to standard triple therapy, both given for 10 days, results were disappointing (eradication rates $65 \%$ versus $78 \%$ on ITT analysis), whereas a higher incidence of adverse events was observed among patients receiving BQT [29].

A practical issue limiting the use of BQT is the absence of HCL tetracycline in some countries and the unavailability of bismuth salts in some other. Substitution of tetracycline with doxycycline or amoxicillin, in order to overcome this problem, was associated with rather disappointing results [81, $82]$. On the contrary, high success rates were reported when BQT was used in the form of one capsule containing bismuth with both the antibiotics (metronidazole plus tetracycline). Three of these monocapsules are given four times daily in combination with a PPI twice daily for 10 days; this bismuthbased triple therapy monocapsule represents a patientfriendly formulation which is aimed to increase compliance to treatment $[83,84]$. Currently, two of these monocapsules are available in the market, Helidac (USA) containing a lower dose of metronidazole ( $1 \mathrm{gr}$ instead of $1.5 \mathrm{gr}$ ) and Pylera (USA and Europe) containing a lower dose of Tetracycline ( $1.5 \mathrm{gr}$ instead of $2 \mathrm{gr}$ ), as compared to the classic BQT. These therapies seem to overcome $H$. pylori resistance to metronidazole since they achieve high eradication rates, reportedly exceeding 90\% [85-88]. 
TABLE 1: Recommended regimens for Helicobacter pylori therapy.

\begin{tabular}{|c|c|}
\hline Treatment & Regimen \\
\hline \multicolumn{2}{|l|}{ First-line treatments } \\
\hline Sequential therapy & $\begin{array}{l}\text { A } 5 \mathrm{~d} \text { dual therapy with a PPI (standard dose, b.i.d.) and amoxicillin ( } 1 \text { g, b.i.d.) } \\
\text { followed by a } 5 \mathrm{~d} \text { triple therapy with a PPI (standard dose, b.i.d.), clarithromycin } \\
\text { ( } 500 \mathrm{mg} \text {, b.i.d.), and metronidazole ( } 500 \mathrm{mg} \text {, b.i.d.) }\end{array}$ \\
\hline Concomitant therapy & $\begin{array}{l}\text { A PPI (standard dose, b.i.d.), clarithromycin ( } 500 \mathrm{mg} \text {, b.i.d.), amoxicillin ( } 1 \text { g, b.i.d.), } \\
\text { and metronidazole ( } 500 \mathrm{mg} \text {, b.i.d.) for } 7-10 \mathrm{~d}\end{array}$ \\
\hline Hybrid therapy & $\begin{array}{l}\text { A } 7 \mathrm{~d} \text { dual therapy with a PPI (standard dose, b.i.d.) and amoxicillin ( } 1 \text { g, b.i.d.) } \\
\text { followed by a } 7 \mathrm{~d} \text { quadruple therapy with a PPI (standard dose, b.i.d.), amoxicillin } \\
\text { ( } 1 \text { g, b.i.d.), clarithromycin }(500 \mathrm{mg} \text {, b.i.d.), and metronidazole }(500 \mathrm{mg} \text {, b.i.d.) }\end{array}$ \\
\hline Bismuth-containing quadruple therapy & $\begin{array}{l}\text { A PPI (standard dose, b.i.d.), bismuth (standard dose, q.i.d.), tetracycline }(500 \mathrm{mg} \text {, } \\
\text { q.i.d.), and metronidazole ( } 500 \mathrm{mg} \text {, t.i.d.) for } 10-14 \mathrm{~d}\end{array}$ \\
\hline \multicolumn{2}{|l|}{ Second-line/Salvage treatments } \\
\hline Levofloxacin-based triple therapy & $\begin{array}{l}\text { A PPI (standard dose, b.i.d.), levofloxacin ( } 500 \mathrm{mg} \text {, b.i.d.), and amoxicillin ( } 1 \mathrm{~g} \text {, } \\
\text { b.i.d.) for } 10 \mathrm{~d}\end{array}$ \\
\hline Bismuth-containing quadruple therapy & $\begin{array}{l}\text { A PPI (standard dose, b.i.d.), bismuth (standard dose, q.i.d.), tetracycline ( } 500 \mathrm{mg} \text {, } \\
\text { q.i.d.), and metronidazole ( } 500 \mathrm{mg} \text {, t.i.d.) for } 14 \mathrm{~d}\end{array}$ \\
\hline Standard triple therapy* & $\begin{array}{l}\text { A PPI (standard dose, b.i.d.), amoxicillin ( } 1 \text { g, b.i.d.), and clarithromycin ( } 500 \mathrm{mg} \text {, } \\
\text { b.i.d.) for } 14 \text { days }\end{array}$ \\
\hline Levofloxacin-based sequential therapy** & $\begin{array}{l}\text { A } 5 \mathrm{~d} \text { dual therapy with a PPI (standard dose, b.i.d.) and amoxicillin ( } 1 \text { g, b.i.d.) } \\
\text { followed by a } 5 \mathrm{~d} \text { triple therapy with a PPI (standard dose, b.i.d.), levofloxacin } \\
(250 \mathrm{mg} \text {, b.i.d.), and amoxicillin ( } 1 \text { g, b.i.d.) }\end{array}$ \\
\hline Amoxicillin-based dual therapy (high dose $)^{\wedge}$ & A PPI (high dose, t.i.d) and Amoxicillin ( $1 \mathrm{~g}$, t.i.d.) for 14 days \\
\hline Rifabutin-based triple therapy ${ }^{\wedge}$ & $\begin{array}{l}\text { A PPI (standard dose, b.i.d.), rifabutin ( } 150 \mathrm{mg} \text { b.i.d.), and amoxicillin ( } 1 \mathrm{~g} \text { b.i.d.) } \\
\text { for } 14 \mathrm{~d}\end{array}$ \\
\hline Furazolidone-based quadruple therapy ${ }^{\wedge}$ & $\begin{array}{l}\text { A PPI (standard dose, b.i.d.), tripotassium dicitratobismuthate }(240 \mathrm{mg} \text {, b.i.d.), } \\
\text { furazolidone ( } 200 \mathrm{mg} \text {, b.i.d.), and tetracycline ( } 1 \mathrm{~g} \text {, b.i.d.) }\end{array}$ \\
\hline
\end{tabular}

${ }^{*}$ Employed after antibiotic susceptibility testing; ${ }^{* *}$ regimen under evaluation; ${ }^{\wedge}$ regimen usually employed as third-line therapy; PPI: proton pump inhibitor.

4.4. Alternative First-Line Therapies. In recent years, some authorities have proposed the use of levofloxacin, instead of clarithromycin, as the main compound of first-line treatments, achieving contradictory results [55, 76, 89]. Indeed, eradication rates with the use of levofloxacin-based triple therapy have been varying from $72 \%$ to $90 \%$ (ITT analysis), and this regimen has been suggested as an efficient alternative in settings of clarithromycin resistance exceeding 15\%-20\% and quinolone resistance less than 10\% [90]. Interestingly, a novel levofloxacin-based sequential regimen was more effective than the standard clarithromycin-based sequential regimen in a setting with a high clarithromycin resistance rate $(20 \%)$ where the latter has yielded suboptimal eradication rates $(<80 \%$ in ITT) [89]. However, it should be noted that primary levofloxacin resistance in the study was very low $(3.7 \%)$, and therefore these results may be difficult to reproduce in geographical areas with higher rates of quinolone resistance. Rapid development of resistance, as well as the high incidence of adverse events, represents further drawbacks concerning the use of levofloxacin in first-line treatment [91-96]. For these reasons, levofloxacin-based regimens are generally considered more suitable for use as second-line treatments or as salvage therapies [90, 97-101].

\section{Therapeutic Algorithm of $H$. pylori Infection in Clinical Practice}

The recommended regimens for $H$. pylori therapies are summarized in Table 1. Choice of the optimal, among these regimens, has to follow the rule of what works best locally; this should be based on the knowledge of the local $H$. pylori resistance pattern and the continuous evaluation of treatment outcomes (posttreatment testing) in clinical practice $[42,102]$. For $5-10 \%$ of patients, even the emerging firstline therapies, described in this paper, are expected to be unsuccessful. In these cases, empiric use of a levofloxacinbased triple therapy seems to represent a reasonable option if local resistance to this antibiotic does not exceed 10\% [102104]. Alternatively, a bismuth-based quadruple therapy can be used for 14 days, since this regimen seems to overcome, at least partially, resistance to metronidazole [105-107]. The old dual regimen of a PPI plus amoxicillin given twice daily (and abandoned because of low eradication rates $(<50 \%)$ ), returns nowadays with the administration of higher doses of both drugs $(\mathrm{PPI} \times 3$ and amoxicillin $1000 \mathrm{mg} \times 3)$. With the new dosing scheme this dual regimen can be used as salvage therapy in areas with high resistance rates to levofloxacin 
[108]. The small minority of patients $(<1 \%)$ with refractory $H$. pylori infection to both first- and second-line treatments have to be referred for antibiotic susceptibility testing in order for third-line therapies to be instituted [104, 109]. Alternatively, rifabutin-based or furazolidone-based therapies can be employed for the treatment of refractory $H$. pylori infection $[110,111]$.

Importantly, most of the aforementioned emerging firstline therapies have not been incorporated into international guidelines so far $[25,77]$, although this does not seem to be too far away according to more recent recommendations [112]. However, there is still work to be done in order for these novel regimens to be sufficiently validated and therefore possibly recommended as first choice therapies ushering in a new era of anti-H. pylori treatment.

\section{References}

[1] P. Moayyedi and R. H. Hunt, "Helicobacter pylori public health implications," Helicobacter, vol. 9, supplement 1, pp. 67-72, 2004.

[2] S. Suerbaum and P. Michetti, "Helicobacter pylori infection," The New England Journal of Medicine, vol. 347, no. 15, pp. 1175-1186, 2002.

[3] L. Fuccio, R. M. Zagari, L. H. Eusebi et al., "Meta-analysis: can Helicobacter pylori eradication treatment reduce the risk for gastric cancer?" Annals of Internal Medicine, vol. 151, no. 2, pp. 121-128, 2009.

[4] K. Fukase, M. Kato, S. Kikuchi et al., "Effect of eradication of Helicobacter pylori on incidence of metachronous gastric carcinoma after endoscopic resection of early gastric cancer: an open-label, randomised controlled trial," The Lancet, vol. 372, no. 9636, pp. 392-397, 2008.

[5] P. Malfertheiner, F. K. Chan, and K. E. McColl, "Peptic ulcer disease," The Lancet, vol. 374, no. 9699, pp. 1449-1461, 2009.

[6] A. Stathis, F. Bertoni, and E. Zucca, "Treatment of gastric marginal zone lymphoma of MALT type," Expert Opinion on Pharmacotherapy, vol. 11, no. 13, pp. 2141-2152, 2010.

[7] D. Y. Graham, "Antibiotic resistance in Helicobacter pylori: implications for therapy," Gastroenterology, vol. 115, no. 5, pp. 1272-1277, 1998.

[8] F. Mégraud, "H pylori antibiotic resistance: prevalence, importance, and advances in testing," Gut, vol. 53, no. 9, pp. 1374-1384, 2004.

[9] F. Megraud, "Helicobacter pylori and antibiotic resistance," Gut, vol. 56, no. 11, p. 1502, 2007.

[10] N. Broutet, S. Tchamgoué, E. Pereira, H. Lamouliatte, R. Salamon, and F. Mégraud, "Risk factors for failure of Helicobacter pylori therapy — results of an individual data analysis of 2751 patients," Alimentary Pharmacology \& Therapeutics, vol. 17, no. 1, pp. 99-109, 2003.

[11] S. D. Georgopoulos, S. D. Ladas, S. Karatapanis et al., "Factors that may affect treatment outcome of triple Helicobacter pylori eradication therapy with omeprazole, amoxicillin, and clarithromycin," Digestive Diseases and Sciences, vol. 45, no. 1, pp. 63-67, 2000.

[12] "Current European concepts in the management of Helicobacter pylori infection. The Maastricht Consensus Report. European Helicobacter Pylori Study Group," Gut, vol. 41, no. 1, pp. 8-13, 1997.
[13] T. Lind, S. V. van Zanten, P. Unge et al., "Eradication of Helicobacter pylori using one-week triple therapies combining omeprazole with two antimicrobials: the MACH I study," Helicobacter, vol. 1, no. 3, pp. 138-144, 1996.

[14] V. De Francesco, M. Margiotta, A. Zullo et al., "Prevalence of primary clarithromycin resistance in Helicobacter pylori strains over a 15 year period in Italy," Journal of Antimicrobial Chemotherapy, vol. 59, no. 4, pp. 783-785, 2007.

[15] J. P. Gisbert, R. Pajares, and J. M. Pajares, "Evolution of Helicobacter pylori therapy from a meta-analytical perspective," Helicobacter, vol. 12, supplement 2, pp. 50-58, 2007.

[16] V. De Francesco, F. Giorgio, C. Hassan et al., "Worldwide H. pylori antibiotic resistance: a systematic review," Journal of Gastrointestinal and Liver Diseases, vol. 19, no. 4, pp. 409414, 2010.

[17] L. A. Fischbach, K. J. Goodman, M. Feldman, and C. Aragaki, "Sources of variation of Helicobacter pylori treatment success in adults worldwide: a meta-analysis," International Journal of Epidemiology, vol. 31, no. 1, pp. 128-139, 2002.

[18] M. J. Janssen, A. H. Van Oijen, A. L. Verbeek, J. B. Jansen, and W. A. De Boer, "A systematic comparison of triple therapies for treatment of Helicobacter pylori infection with proton pump inhibitor/ranitidine bismuth citrate plus clarithromycin and either amoxicillin or a nitroimidazole," Alimentary Pharmacology \& Therapeutics, vol. 15, no. 5, pp. 613-624, 2001.

[19] R. J. Laheij, L. G. Rossum, J. B. Jansen, H. Straatman, and A. L. Verbeek, "Evaluation of treatment regimens to cure Helicobacter pylori infection-a meta-analysis," Alimentary Pharmacology \& Therapeutics, vol. 13, no. 7, pp. 857-864, 1999.

[20] P. Malfertheiner, F. Mégraud, C. O’Morain et al., "Current concepts in the management of Helicobacter pylori infection-the Maastricht 2-2000 Consensus Report," Alimentary Pharmacology \& Therapeutics, vol. 16, no. 2, pp. 167-180, 2002.

[21] P. H. Katelaris, G. M. Forbes, N. J. Talley, and B. Crotty, "A randomized comparison of quadruple and triple therapies for Helicobacter pylori eradication: the QUADRATE study," Gastroenterology, vol. 123, no. 6, pp. 1763-1769, 2002.

[22] X. Calvet, J. Ducons, J. Guardiola et al., "One-week triple vs. quadruple therapy for Helicobacter pylori infection-a randomized trial," Alimentary Pharmacology \& Therapeutics, vol. 16, no. 7, pp. 1261-1267, 2002.

[23] J. Luther, P. D. Higgins, P. S. Schoenfeld, P. Moayyedi, N. Vakil, and W. D. Chey, "Empiric quadruple vs. triple therapy for primary treatment of Helicobacter pylori infection: systematic review and meta-analysis of efficacy and tolerability," American Journal of Gastroenterology, vol. 105, no. 1, pp. 6573, 2010.

[24] D. Y. Graham and M. P. Dore, "Helicobacter pylori therapy demystified," Helicobacter, vol. 16, no. 5, pp. 343-345, 2011.

[25] W. D. Chey and B. C. Wong, "American College of Gastroenterology guideline on the management of Helicobacter pylori infection," American Journal of Gastroenterology, vol. 102, no. 8, pp. 1808-1825, 2007.

[26] M. Caselli, A. Zullo, G. Maconi et al., "Cervia II Working Group Report 2006': guidelines on diagnosis and treatment of Helicobacter pylori infection in Italy," Digestive and Liver Disease, vol. 39, no. 8, pp. 782-789, 2007.

[27] G. Maconi, C. Tosetti, G. Miroglio et al., "Management of Helicobacter pylori-related gastrointestinal diseases by general practitioners in Italy," Alimentary Pharmacology \& Therapeutics, vol. 13, no. 11, pp. 1499-1504, 1999. 
[28] S. D. Georgopoulos, S. D. Ladas, S. Karatapanis et al., "Effectiveness of two quadruple, tetracycline- or clarithromycincontaining, second-line, Helicobacter pylori eradication therapies," Alimentary Pharmacology \& Therapeutics, vol. 16, no. 3, pp. 569-575, 2002.

[29] G. J. Mantzaris, K. Petraki, E. Archavlis et al., "Omeprazole triple therapy versus omeprazole quadruple therapy for healing duodenal ulcer and eradication of Helicobacter pylori infection: 24-month follow-up study," European Journal of Gastroenterology and Hepatology, vol. 14, no. 11, pp. 12371243, 2002.

[30] S. Karatapanis, S. D. Georgopoulos, V. Papastergiou et al., "7, 10 and 14-days rabeprazole-based standard triple therapies for $\mathrm{H}$. pylori eradication: are they still effective? A randomized trial," Acta Gastroenterol Belg, vol. 74, no. 3, pp. 407-412, 2011.

[31] T. Rokkas, P. Sechopoulos, I. Robotis, G. Margantinis, and D. Pistiolas, "Cumulative H. pylori eradication rates in clinical practice by adopting first and second-line regimens proposed by the Maastricht III consensus and a third-line empirical regimen," American Journal of Gastroenterology, vol. 104, no. 1, pp. 21-25, 2009.

[32] L. Boyanova, A. Mentis, M. Gubina et al., "The status of antimicrobial resistance of Helicobacter pylori in Eastern Europe," Clinical Microbiology and Infection, vol. 8, no. 7, pp. 388-396, 2002.

[33] Y. Glupczynski, F. Mégraud, M. Lopez-Brea, and L. P. Andersen, "European multicentre survey of in vitro antimicrobial resistance in Helicobacter pylori," European Journal of Clinical Microbiology and Infectious Diseases, vol. 20, no. 11, pp. 820-823, 2001.

[34] A. F. Mentis, E. Roma, A. Pangalis, and E. Katsiyiannakis, "Susceptibilities of Helicobacter pylori strains isolated from children with gastritis to selected antibiotics," Journal of Antimicrobial Chemotherapy, vol. 44, no. 5, pp. 720-722, 1999.

[35] J. P. Gisbert, J. L. Gisbert, S. Marcos, I. Jimenez-Alonso, R. Moreno-Otero, and J. M. Pajares, "Empirical rescue therapy after Helicobacter pylori treatment failure: a 10-year singlecentre study of 500 patients," Alimentary Pharmacology \& Therapeutics, vol. 27, no. 4, pp. 346-354, 2008.

[36] K. Seppälä, T. U. Kosunen, L. Veijola et al., "Cure of Helicobacter pylori infection in all compliant patients: report on 644 subjects," Scandinavian Journal of Gastroenterology, vol. 43, no. 9, pp. 1149-1150, 2008.

[37] L. Fuccio, R. M. Zagari, and F. Bazzoli, "What is the best salvage therapy for patients with Helicobacter pylori infection?" Nature Clinical Practice Gastroenterology and Hepatology, vol. 5, no. 11, pp. 608-609, 2008.

[38] J. Q. Huang and R. H. Hunt, "Treatment after failure: the problem of 'non-responders', Gut, vol. 45, supplement 1, pp. I40-I44, 1999.

[39] S. K. Chuah, F. W. Tsay, P. I. Hsu, and D. C. Wu, "A new look at anti-Helicobacter pylori therapy," World Journal of Gastroenterology, vol. 17, no. 35, pp. 3971-3975, 2011.

[40] D. Y. Graham, H. Lu, and Y. Yamaoka, "A report card to grade Helicobacter pylori therapy," Helicobacter, vol. 12, no. 4, pp. 275-278, 2007.

[41] D. Y. Graham, "Efficient identification and evaluation of effective Helicobacter pylori therapies," Clinical Gastroenterology and Hepatology, vol. 7, no. 2, pp. 145-148, 2009.

[42] D. Y. Graham and L. Fischbach, "Helicobacter pylori treatment in the era of increasing antibiotic resistance," Gut, vol. 59, no. 8, pp. 1143-1153, 2010.
[43] J. P. Gisbert, X. Calvet, A. O’Connor, F. Mégraud, and C. A. O’Morain, "Sequential therapy for Helicobacter pylori eradication: a critical review," Journal of Clinical Gastroenterology, vol. 44, no. 5, pp. 313-325, 2010.

[44] P. Moayyedi, "Sequential regimens for Helicobacter pylori eradication," The Lancet, vol. 370, no. 9592, pp. 1010-1012, 2007.

[45] N. S. Jafri, C. A. Hornung, and C. W. Howden, "Metaanalysis: sequential therapy appears superior to standard therapy for Helicobacter pylori infection in patients naive to treatment," Annals of Internal Medicine, vol. 148, no. 12, pp. 923-931, 2008.

[46] J. L. Tong, Z. H. Ran, J. Shen, and S. D. Xiao, "Sequential therapy vs. standard triple therapies for Helicobacter pylori infection: a meta-analysis," Journal of Clinical Pharmacy and Therapeutics, vol. 34, no. 1, pp. 41-53, 2009.

[47] L. Gatta, N. Vakil, G. Leandro, F. Di Mario, and D. Vaira, "Sequential therapy or triple therapy for Helicobacter pylori infection: systematic review and meta-analysis of randomized controlled trials in adults and children," American Journal of Gastroenterology, vol. 104, no. 12, pp. 3069-3079, 2009.

[48] A. Zullo, V. De Francesco, C. Hassan, S. Morini, and D. Vaira, "The sequential therapy regimen for Helicobacter pylori eradication: a pooled-data analysis," Gut, vol. 56, no. 10, pp. 1353-1357, 2007.

[49] D. Vaira, A. Zullo, N. Vakil et al., "Sequential therapy versus standard triple-drug therapy for Helicobacter pylori eradication: a randomized trial," Annals of Internal Medicine, vol. 146, no. 8, pp. 556-563, 2007.

[50] D. C. Wu, P. I. Hsu, J. Y. Wu et al., "Sequential and concomitant therapy with four drugs is equally effective for eradication of $\mathrm{H}$ pylori infection," Clinical Gastroenterology and Hepatology, vol. 8, no. 1, pp. 36.e1-41.e1, 2010.

[51] I. T. Paulsen, M. H. Brown, and R. A. Skurray, "Protondependent multidrug efflux systems," Microbiological Reviews, vol. 60, no. 4, pp. 575-608, 1996.

[52] M. A. Webber and L. J. Piddock, "The importance of efflux pumps in bacterial antibiotic resistance," Journal of Antimicrobial Chemotherapy, vol. 51, no. 1, pp. 9-11, 2003.

[53] M. C. Roberts, "Resistance to macrolide, lincosamide, streptogramin, ketolide, and oxazolidinone antibiotics," Molecular Biotechnology, vol. 28, no. 1, pp. 47-62, 2004.

[54] J. Molina-Infante, C. Pazos-Pacheco, and B. Perez-Gallardo, "Efficacy of nonbismuth quadruple "concomitant" therapy for H. pylori infection in a setting with high clarithromycin resistance," Helicobacter, vol. 138, article 880, supplement 1, 2011.

[55] J. Molina-Infante, B. Perez-Gallardo, M. Fernandez-Bermejo et al., "Clinical trial: clarithromycin vs. levofloxacin in firstline triple and sequential regimens for Helicobacter pylori eradication," Alimentary Pharmacology \& Therapeutics, vol. 31, no. 10, pp. 1077-1084, 2010.

[56] W. A. de Boer, E. J. Kuipers, and J. G. Kusters, "Sequential therapy; a new treatment for Helicobacter pylori infection: but is it ready for general use?" Digestive and Liver Disease, vol. 36, no. 5, pp. 311-314, 2004.

[57] J. Sánchez-Delgado, X. Calvet, L. Bujanda, J. P. Gisbert, L. Titó, and M. Castro, "Ten-day sequential treatment for Helicobacter pylori eradication in clinical practice," American Journal of Gastroenterology, vol. 103, no. 9, pp. 2220-2223, 2008.

[58] C. A. O’Morain and J. P. O'Connor, "Is sequential therapy superior to standard triple therapy for the treatment 
of Helicobacter pylori infection?" Nature Clinical Practice Gastroenterology and Hepatology, vol. 6, no. 1, pp. 8-9, 2009.

[59] P. Moayyedi and P. Malfertheiner, "Editorial: sequential therapy for eradication of Helicobacter pylori: a new guiding light or a false dawn?" American Journal of Gastroenterology, vol. 104, no. 12, pp. 3081-3083, 2009.

[60] J. Luther and W. D. Chey, "Sequential therapy for Helicobacter pylori: a two for one deal that's worth the extra effort?" Gastroenterology, vol. 136, no. 2, pp. 720-722, 2009.

[61] W. H. Choi, D. I. Park, S. J. Oh et al., "Effectiveness of 10 day-sequential therapy for Helicobacter pylori eradication in Korea," The Korean Journal of Gastroenterology, vol. 51, no. 5, pp. 280-284, 2008.

[62] X. Z. Gao, X. L. Qiao, W. C. Song, X. F. Wang, and F. Liu, "Standard triple, bismuth pectin quadruple and sequential therapies for Helicobacter pylori eradication," World Journal of Gastroenterology, vol. 16, no. 34, pp. 4357-4362, 2010.

[63] E. R. Greenberg, G. L. Anderson, D. R. Morgan et al., "14-day triple, 5-day concomitant, and 10-day sequential therapies for Helicobacter pylori infection in seven Latin American sites: a randomised trial," The Lancet, vol. 378, no. 9790, pp. 507-514, 2011.

[64] D. Y. Graham and E. Rimbara, "Understanding and appreciating sequential therapy for Helicobacter pylori eradication," Journal of Clinical Gastroenterology, vol. 45, no. 4, pp. 309313, 2011.

[65] H. G. Park, M. K. Jung, J. T. Jung et al., "Randomised clinical trial: a comparative study of 10-day sequential therapy with 7-day standard triple therapy for Helicobacter pylori infection in naive patients," Alimentary Pharmacology \& Therapeutics, vol. 35, no. 1, pp. 56-65, 2012.

[66] A. Merali and G. I. Leontiadis, "Sequential therapy-more studies are still required," Alimentary Pharmacology \& Therapeutics, vol. 35, no. 1, pp. 194-195, 2012.

[67] J. P. Gisbert and X. Calvet, "Review article: non-bismuth quadruple (concomitant) therapy for eradication of Helicobater pylori," Alimentary Pharmacology \& Therapeutics, vol. 34, no. 6, pp. 604-617, 2011.

[68] H. Fakheri, T. Taghvaei, V. Hosseini, and Z. Bari, "A comparison between sequential therapy and a modified bismuthbased quadruple therapy for Helicobacter pylori eradication in Iran: a randomized clinical trial," Helicobacter, vol. 17, no. 1, pp. 43-48, 2012.

[69] D. Y. Graham and A. Shiotani, "New concepts of resistance in the treatment of Helicobacter pylori infections," Nature Clinical Practice Gastroenterology and Hepatology, vol. 5, no. 6, pp. 321-331, 2008.

[70] G. Treiber, J. Wittig, S. Ammon, S. Walker, L. J. van Doorn, and U. Klotz, "Clinical outcome and influencing factors of a new short-term quadruple therapy for Helicobacter pylori eradication: a randomized controlled trial (MACLOR study)," Archives of Internal Medicine, vol. 162, no. 2, pp. 153-160, 2002.

[71] A. S. Essa, J. R. Kramer, D. Y. Graham, and G. Treiber, "Metaanalysis: four-drug, three-antibiotic, non-bismuth-containing "concomitant therapy" versus triple therapy for Helicobacter pylori eradication," Helicobacter, vol. 14, no. 2, pp. 109-118, 2009.

[72] L. A. Fischbach, L. E. Bravo, G. R. Zarama et al., "A randomized clinical trial to determine the efficacy of regimens containing clarithromycin, metronidazole, and amoxicillin among histologic subgroups for Helicobacter pylori eradication in a developing country," Helicobacter, vol. 14, no. 2, pp. 100-108, 2009.
[73] P. I. Hsu, D. C. Wu, J. Y. Wu, and D. Y. Graham, "Modified sequential Helicobacter pylori therapy: proton pump inhibitor and amoxicilin for 14 days with clarithromycin and metronidazole added as a quadruple (hybrid) therapy for the final 7 days," Helicobacter, vol. 16, no. 2, pp. 146-152, 2011.

[74] S. Georgopoulos, V. Papastergiou, E. Xirouchakis et al., "Evaluation of a four-drug, three-antibiotic, nonbismuthcontaining "concomitant" therapy as first-line Helicobacter pylori eradication regimen in Greece," Helicobacter, vol. 16, no. 2, pp. 139-145, 2011.

[75] S. D. Georgopoulos, E. Xirouchakis, and F. Laoudi, "Clinical evaluation of a 10-day regimenwith esomeprazole, metronidazole, amoxycilline and clarithromycin for the eradication of Helicobacter pylori (E-MACH study)," Helicobacter, vol. 16, article A136, supplement 1, 2011.

[76] J. M. Liou, J. T. Lin, C. Y. Chang et al., "Levofloxacin-based and clarithromycin-based triple therapies as first-line and second-line treatments for Helicobacter pylori infection: a randomised comparative trial with crossover design," Gut, vol. 59, no. 5, pp. 572-578, 2010.

[77] P. Malfertheiner, F. Megraud, C. O’Morain et al., "Current concepts in the management of Helicobacter pylori infection: the Maastricht III Consensus Report," Gut, vol. 56, no. 6, pp. 772-781, 2007.

[78] L. A. Fischbach, S. van Zanten, and J. Dickason, "Metaanalysis: the efficacy, adverse events, and adherence related to first-line anti-Helicobacter pylori quadruple therapies," Alimentary Pharmacology \& Therapeutics, vol. 20, no. 10, pp. 1071-1082, 2004.

[79] L. Fischbach and E. L. Evans, "Meta-analysis: the effect of antibiotic resistance status on the efficacy of triple and quadruple first-line therapies for Helicobacter pylori," Alimentary Pharmacology \& Therapeutics, vol. 26, no. 3, pp. 343-357, 2007.

[80] S. Michopoulos, P. Tsibouris, H. Bouzakis et al., "Randomized study comparing omeprazole with ranitidine as anti-secretory agents combined in quadruple second-Iine Helicobacter pylori eradication regimens," Alimentary Pharmacology \& Therapeutics, vol. 14, no. 6, pp. 737-744, 2000.

[81] F. Perri, V. Festa, A. Merla, M. Quitadamo, R. Clemente, and A. Andriulli, "Amoxicillin/tetracycline combinations are inadequate as alternative therapies for Helicobacter pylori infection," Helicobacter, vol. 7, no. 2, pp. 99-104, 2002.

[82] N. Garcia, X. Calvet, E. Gene, R. Campo, and E. Brullet, "Limited usefulness of a seven-day twice-a-day quadruple therapy," European Journal of Gastroenterology and Hepatology, vol. 12, no. 12, pp. 1315-1318, 2000.

[83] W. A. de Boer, R. J. van Etten, P. M. Schneeberger, and G. N. Tytgat, "A single drug for Helicobacter pylori infection: first results with a new bismuth triple monocapsule," American Journal of Gastroenterology, vol. 95, no. 3, pp. 641-645, 2000.

[84] W. A. de Boer, "A novel therapeutic approach for Helicobacter pylori infection: the bismuth-based triple therapy monocapsule," Expert Opinion on Investigational Drugs, vol. 10, no. 8, pp. 1559-1566, 2001.

[85] L. Laine, R. Hunt, H. EI-Zimaity, B. Nguyen, M. Osato, and J. Spénard, "Bismuth-based quadruple therapy using a single capsule of bismuth biskalcitrate, metronidazole, and tetracycline given with omeprazole versus omeprazole, amoxicillin, and clarithromycin for eradication of Helicobacter pylori in duodenal ulcer patients: a prospective, randomized, multicenter, North American trial," American Journal of Gastroenterology, vol. 98, no. 3, pp. 562-567, 2003. 
[86] C. O’Morain, T. Borody, A. Farley et al., "Efficacy and safety of single-triple capsules of bismuth biskalcitrate, metronidazole and tetracycline, given with omeprazole, for the eradication of Helicobacter pylori: an international multicentre study," Alimentary Pharmacology \& Therapeutics, vol. 17, no. 3, pp. 415-420, 2003.

[87] A. Saleem, A. Qasim, H. J. O'Connor, and C. A. O'Morain, "Pylera for the eradication of Helicobacter pylori infection," Expert Review of Anti-Infective Therapy, vol. 7, no. 7, pp. 793799, 2009.

[88] P. Malfertheiner, F. Bazzoli, J. C. Delchier et al., "Helicobacter pylori eradication with a capsule containing bismuth subcitrate potassium, metronidazole, and tetracycline given with omeprazole versus clarithromycin-based triple therapy: a randomised, open-label, non-inferiority, phase 3 trial," The Lancet, vol. 377, no. 9769, pp. 905-913, 2011.

[89] M. Romano, A. Cuomo, A. G. Gravina et al., "Empirical levofloxacin-containing versus clarithromycin-containing sequential therapy for Helicobacter pylori eradication: a randomised trial," Gut, vol. 59, no. 11, pp. 1465-1470, 2010.

[90] M. Berning, S. Krasz, and S. Miehlke, "Should quinolones come first in Helicobacter pylori therapy?" Therapeutic Advances in Gastroenterology, vol. 4, no. 2, pp. 103-114, 2011.

[91] F. Perna, A. Zullo, C. Ricci, C. Hassan, S. Morini, and D. Vaira, "Levofloxacin-based triple therapy for Helicobacter pylori re-treatment: role of bacterial resistance," Digestive and Liver Disease, vol. 39, no. 11, pp. 1001-1005, 2007.

[92] P. Bogaerts, C. Berhin, H. Nizet, and Y. Glupczynski, "Prevalence and mechanisms of resistance to fluoroquinolones in Helicobacter pylori strains from patients living in Belgium," Helicobacter, vol. 11, no. 5, pp. 441-445, 2006.

[93] J. J. Carothers, M. G. Bruce, T. W. Hennessy et al., "The relationship between previous fluoroquinolone use and levofloxacin resistance in Helicobacter pylori infection," Clinical Infectious Diseases, vol. 44, no. 2, pp. e5-e8, 2007.

[94] P. D. van der Linden, M. C. Sturkenboom, R. M. Herings, H. G. Leufkens, and B. H. Stricker, "Fluoroquinolones and risk of achilles tendon disorders: case-control study," British Medical Journal, vol. 324, no. 7349, pp. 1306-1307, 2002.

[95] K. F. Croom and K. L. Goa, "Levofloxacin: a review of its use in the treatment of bacterial infections in the United States," Drugs, vol. 63, no. 24, pp. 2769-2802, 2003.

[96] C. Bilardi, P. Dulbecco, P. Zentilin et al., "A 10-day levofloxacin-based therapy in patients with resistant Helicobacter pylori infection: a controlled trial," Clinical Gastroenterology and Hepatology, vol. 2, no. 11, pp. 997-1002, 2004.

[97] R. J. Saad, P. Schoenfeld, H. M. Kim, and W. D. Chey, "Levofloxacin-based triple therapy versus bismuth-based quadruple therapy for persistent Helicobacter pylori infection: a meta-analysis," American Journal of Gastroenterology, vol. 101, no. 3, pp. 488-496, 2006.

[98] J. P. Gisbert, F. Bermejo, M. Castro-Fernández et al., "Secondline rescue therapy with levofloxacin after $\mathrm{H}$. pylori treatment failure: a Spanish multicenter study of 300 patients," American Journal of Gastroenterology, vol. 103, no. 1, pp. 71$76,2008$.

[99] J. P. Gisbert, "Second-line rescue therapy of Helicobacter pylori infection," Therapeutic Advances in Gastroenterology, vol. 2, no. 6, pp. 331-356, 2009.

[100] J. P. Gisbert, J. L. Gisbert, S. Marcos, R. Moreno-Otero, and J. M. Pajares, "Third-line rescue therapy with levofloxacin is more effective than rifabutin rescue regimen after two Helicobacter pylori treatment failures," Alimentary Pharmacology \& Therapeutics, vol. 24, no. 10, pp. 1469-1474, 2006.
[101] T. Nishizawa, H. Suzuki, and T. Hibi, "Quinolone-based third-line therapy for Helicobacter pylori eradication," Journal of Clinical Biochemistry and Nutrition, vol. 44, no. 2, pp. 119-124, 2009.

[102] S. Karatapanis, L. Skorda, S. D. Georgopoulos et al., "Levofloxacin-based triple therapy versus bismuth-based quadruple therapy as a second line treatment for the eradication of H. pylori infection," Annals of Gastroenterology, vol. 22, no. 4, pp. 263-267, 2009.

[103] C. Krystallis, D. Kamberoglou, D. Pistiolas et al., "A new second-line sequential regimen for Helicobacter pylori eradication based on levofloxacin: a pilot study," Digestive Diseases and Sciences, vol. 55, no. 12, pp. 3630-3631, 2010.

[104] S. Pontone, M. Standoli, R. Angelini, and P. Pontone, "Efficacy of $\mathrm{H}$. pylori eradication with a sequential regimen followed by rescue therapy in clinical practice," Digestive and Liver Disease, vol. 42, no. 8, pp. 541-543, 2010.

[105] D. Y. Graham, M. S. Osato, J. Hoffman et al., "Metronidazole containing quadruple therapy for infection with metronidazole resistant Helicobacter pylori: a prospective study," Alimentary Pharmacology \& Therapeutics, vol. 14, no. 6, pp. 745-750, 2000.

[106] B. H. Lee, N. Kim, T. J. Hwang et al., "Bismuth-containing quadruple therapy as second-line treatment for Helicobacter pylori infection: effect of treatment duration and antibiotic resistance on the eradication rate in Korea," Helicobacter, vol. 15, no. 1, pp. 38-45, 2010.

[107] Q. Sun, X. Liang, Q. Zheng et al., "High efficacy of 14-day triple therapy-based, bismuth-containing quadruple therapy for initial Helicobacter pylori eradication," Helicobacter, vol. 15, no. 3, pp. 233-238, 2010.

[108] D. Y. Graham, S. U. Javed, S. Keihanian, S. Abudayyeh, and A. R. Opekun, "Dual proton pump inhibitor plus amoxicillin as an empiric anti-H. pylori therapy: studies from the United States," Journal of Gastroenterology, vol. 45, no. 8, pp. 816820, 2010.

[109] E. Rimbara, L. A. Fischbach, and D. Y. Graham, "Optimal therapy for Helicobacter pylori infections," Nature Reviews Gastroenterology and Hepatology, vol. 8, no. 2, pp. 79-88, 2011.

[110] J. P. Gisbert and X. Calvet, "Review article: rifabutin in the treatment of refractory Helicobacter pylori infection," Alimentary Pharmacology \& Therapeutics, vol. 35, no. 2, pp. 209-221, 2012.

[111] G. Treiber, S. Ammon, P. Malfertheiner, and U. Klotz, "Impact of furazolidone-based quadruple therapy for eradication of Helicobacter pylori after previous treatment failures," Helicobacter, vol. 7, no. 4, pp. 225-231, 2002.

[112] P. Malfertheiner, F. Megraud, C. A. O’Morain et al., "Management of Helicobacter pylori infection-the Maastricht IV/ Florence Consensus Report," Gut, vol. 61, no. 5, pp. 646-664, 2012. 


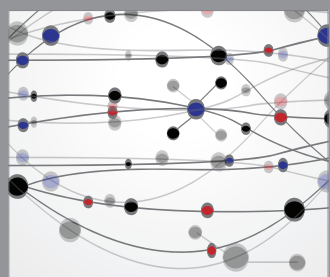

The Scientific World Journal
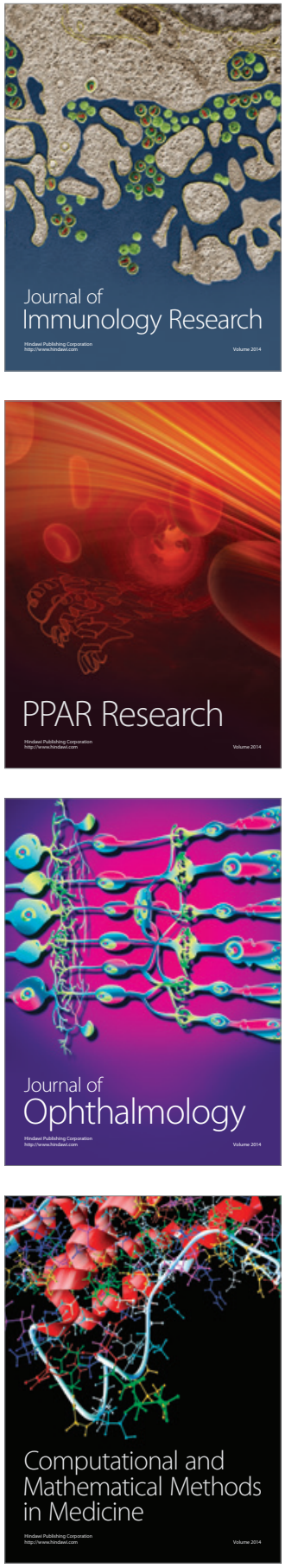

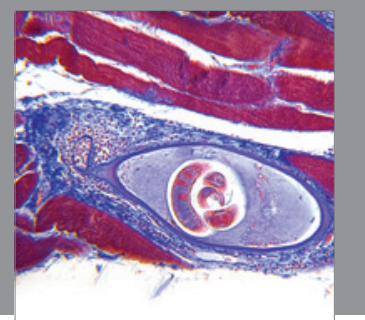

Gastroenterology

Research and Practice
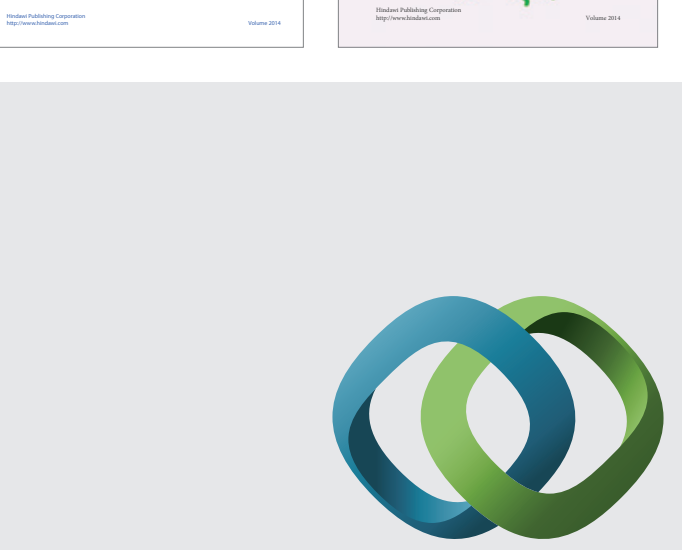

\section{Hindawi}

Submit your manuscripts at

http://www.hindawi.com
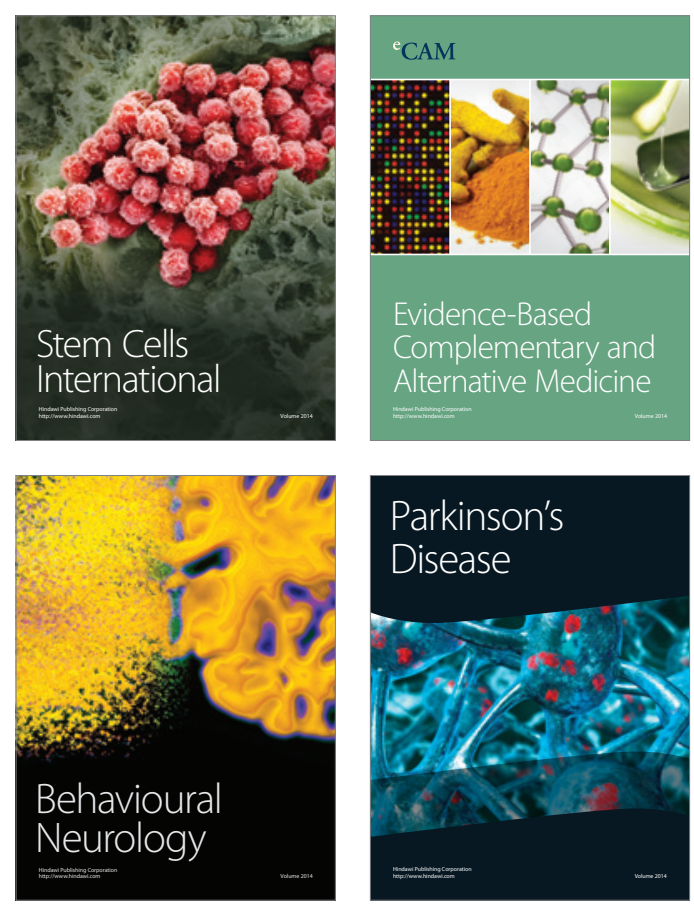

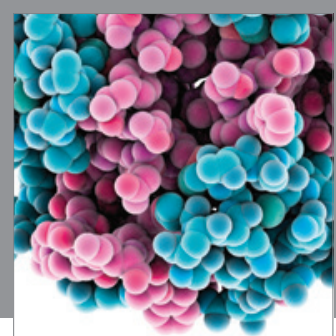

Journal of
Diabetes Research

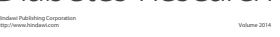

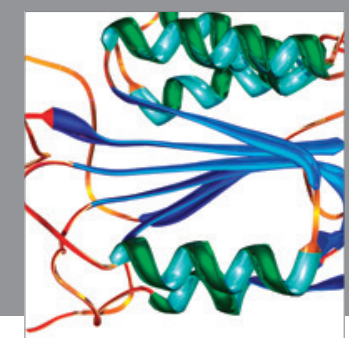

Disease Markers
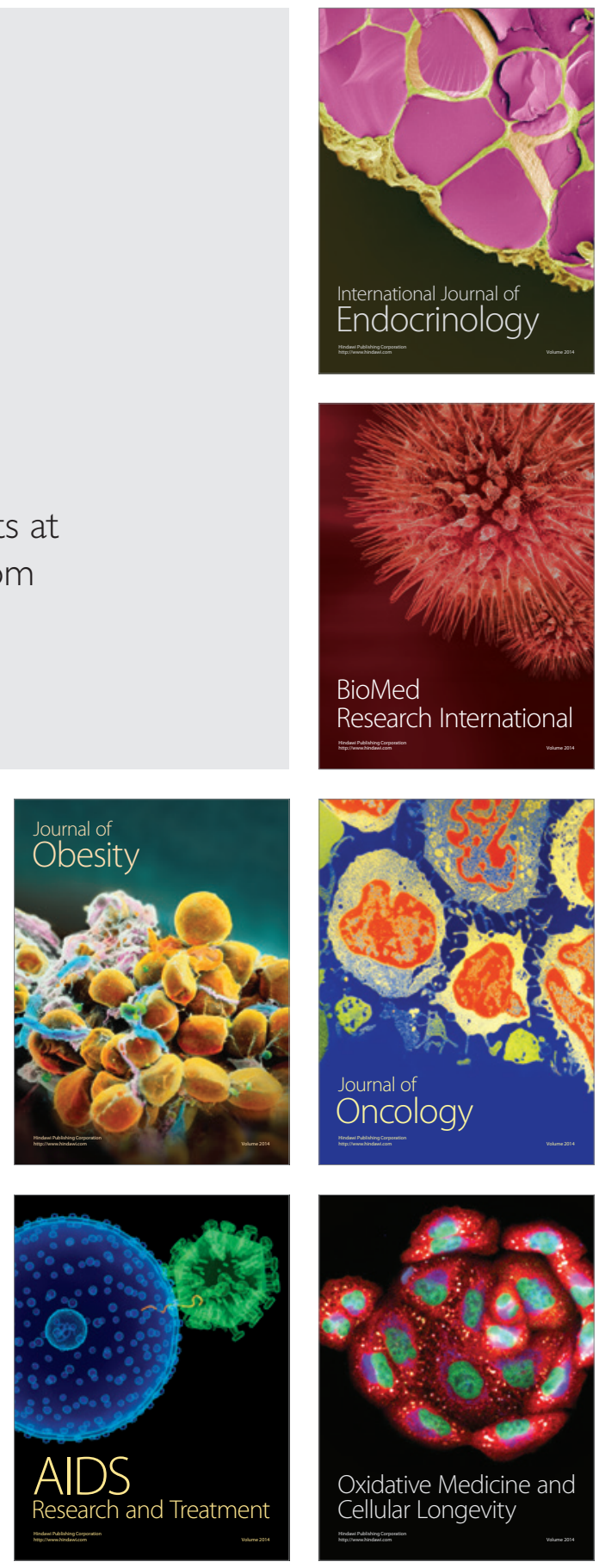